гипербола - 6 слов, фразеологизм - 20 слов, архаизм - 7 слов, историзм - 11 слов. Преобладают эпитеты, так как именно они помогают более красочно описать какие-либо ситуации, например, поединки, путешествия, битвы и т.д. Так же мы можем наблюдать большое количество фразеологизмов, устойчивых оборотов речи, и устаревших слов (архаизмов и историзмов), что является нормой для древних сказаний. Так же большую роль в мифах играет использование гипербол, так как благодаря им происходит усиление выразительности сказанной мысли, что показывает читателям насколько были велики и могучи главные герои мифов.

Подводя итоги, проведенного исследования отметим, что полученные результаты показали, что основными проблемами мифа «Путешествие Тора в Утгард» являются: 1) проблема веры в себя; 2) проблемы как «Каждый имеет две стороны: хорошую и плохую», «Запретный плод сладок» и многие другие, которые мы рассмотрим в будущем исследовании.

\title{
Заключение.
}

В ходе нашего исследования мы пришли к выводу, что в наше время использование такого средства выразительности, как эпитет не уменьшилось, так как до сих пор эпитеты играют огромную роль в написании произведений. Фразеологизмы можно встретить часто в разговорной речи.

Также следует обратить внимание на то, что проблематика мифов соответствует проблематике, описанной в современных произведениях. Решение проблем, связанных с понимание человека, всегда будет актуальным.

В заключении отметим, что изучение мифов является не только интересным, но и полезным занятием, так как в них можно проследить историю, традиции, обычаи, интересы родного и любого иностранного языков.

$$
* * *
$$

1. Мифологический словарь. под ред. Мелетинского Е.М. М.: БРЭ, ЛАДА-МАКОМ, 1992. 736 с.

2. https://ru.wikipedia.org/wiki/\%D0\%A1\%D0\%BA\%D0\%B0\%D0\%BD\%D0\%B4\%D0\%B8\%D0\%BD\%D0\%B0\%D 0\%B2\%D1\%81\%D0\%BA\%D0\%B0\%D1\%8F_\%D0\%BC\%D0\%B8\%D1\%84\%D0\%BE\%D0\%BB\%D0\%BE\%D0 \%B3\%D0\%B8\%D1\%8F (дата обращения: 28.11.2021).

3. https://litportal.ru/avtory/lui-stouell/read/page/1/kniga-skandinavskie-mify-dlya-detey-1030234.html _ _ата обращения: 29.10.2021).

4. https://vseskazki.su/skandinavskie-mify/puteshestvie-tora-v-utgard.html (дата обращения: 19.11.2021).

5. Семенова С.Н. Тезаурус жанра рассказ как произведения художественной литературы (на материале рассказов Дж. Лондона «Безмолвие» и «Сын Волка» на английском, армянском и русском языках) // Филологические науки. Научные доклады высшей школы. М: ИНОИЦ «АЛМАВЕСТ», 2017. № 2. С. 28-37. DOI: $10.20339 / \mathrm{PhS} .2-17.028$.

6. Семенова С.Н. Тезаурус жанра сказка (на материале произведения А.С. Пушкина «Сказка о рыбаке и рыбке» на русском, армянском и английском языках) // Вестник Российского университета дружбы народов. Серия: Теория языка. Семиотика. Семантика. 2017. Т. 8. №2. С. 293-300. doi: 10.22363/2313-2299-2017-8-2-293-300.

\section{Овчинникова Е.В. \\ Аффективы как средства выражения проявлений радости и нерадости в русском и английском языках}

Волгоградский государственный университет (Россия, Волгоград)

doi: 10.18411/trnio-01-2022-116

\section{Аннотация}

В статье описываются причины и способы проявления эмоциональных состояний радости и нерадости на материале текстов классической русской и английской литературы. На основе характеристики причин, вызывающих то или иное эмоциональное проявление, выделены типичные ситуации в рамках радости и нерадости, испытываемых субъектом. 
Рассмотрена группа аффективных языковых средств, выражающих обозначенные ситуации, на примере которой описаны сходства и различия в объективации проявлений эмоций радости и нерадости в русском и английском языках.

Ключевые слова: эмотиология, радость, нерадость, аффективные языковые средства.

\section{Abstract}

The article describes the causes and ways of manifestation of emotional states of joy and non-joy based on the texts of classical Russian and English literature. Based on the characteristics of the reasons causing this or that emotional manifestation, typical situations within the framework of joy and non-joy experienced by the subject are highlighted. A group of effective language means expressing the designated situations is considered, by the example of which similarities and differences in the objectification of manifestations of emotions of joy and non-joy in the Russian and English languages are described.

Keywords: emotionology, joy, non-joy, affective language tools.

Эмоции человека - один из способов выражения его мыслей и чувств, который также может быть вербализирован. Без эмоций ни одна информация, передаваемая человеком, не будет полной. Благодаря способности чувствовать и транслировать особенности своего состояния посредством эмоций человек может даже в письменной форме подать одну и ту же информацию совершенно по-разному, что влияет на ее конечное восприятие реципиентом - читателем или слушателем. На взаимосвязь языковой деятельности и эмоций человека обратили внимание и лингвисты, таким образом создав в научно-лингвистическом дискурсе одно из наиболее актуальных на сегодня исследовательских направлений - эмотиологию.

Однако к пониманию важности эмоциональной оставляющей в процессе передачи информации как на русском, так и на английском языках, лингвисты подходили постепенно. Важным в данном случае стал поворот научной парадигмы к проблемам антропоцентризма, в частности признание ключевой роли человека в процессах развития и изменения языков, что привело к изучению последних в тесной связи с деятельностью людей.

Эмоции, эмоциональная деятельность и способы их вербализации рассматривались учеными на материале как русского, так и других языков, в частности английского. В данной работе характеризуются универсальные эмоции радости и нерадости и различные способы их репрезентации в русском и английском языках. Следует заметить, что радость достаточно часто становилась предметом исследования, в отличие от нерадости.

Эмоцию «радость» и ее антипод «нерадость» американский специалист в области лингвопсихологии К. Изард, относит к разряду основных и наиболее распространенных [1]. Прежде чем приступать к определению причин и способов их транслирования в русской и английской литературе, необходимо понять, что составляет суть данных эмоций. Без сомнений, радость - это положительная эмоция, в основе которой лежит чувство удовлетворения чем-либо. Нерадость - с лингвистической точки зрения антоним, с понятийной - противоположная эмоция неудовлетворенности чем-либо [4]. Обе они также могут быть охарактеризованы как эмоции, которые человек не стремится испытать намеренно. Эти чувства возникают как следствие, например, достижения / недостижения какого-либо результата.

Необходимо также отметить, что радость / нерадость с точки зрения восприятия и понимания являются достаточно универсальными эмоциями для двух языков - русского и английского. При этом в процессе анализа все же необходимо иметь в виду, что наиболее постоянными константами в процессе восприятия эмоциональных состояний человека является совокупность транслируемых им экспрессивных кодов, что приводит нас к выводу о необходимости обязательного учета не только лингвистической составляющей, но и культурной. Так, например, даже универсальные эмоции радости и нерадости в силу разного социокультурного кода у носителей английского и русского языка при их выражении могут приобретать лингвокульутрную специфичность. 
Радость и нерадость - эмоции, имеющие градацию по степени интенсивности, у каждой из которых может быть свое дополнительное название [5]. Рассмотрим некоторые формы радости. Так, веселье можно определить как радость, выражаемую в умеренной степени. В английском языке данной градации соответствуют лексемы «fun», «gladness». Более интенсивное проявление радости - это наслаждение или радость-удовольствие, чему в английском языке соответствует лексема «јоу». Еще более интенсивная форма радости восхищение или «delight» соответственно. Наивысшей формой радости, пиком ее проявления является счастье, чему в английском языке соответствует лексема «happiness».

О градации по степени интенсивности мы можем говорить и в случае эмоции «нерадость». Так, одним из наиболее простых выражений нерадости является грусть или «sadness», более интенсивным - сожаление или «regret», еще более интенсивным - скорбь или «sorrow». Наивысшей же степенью проявления нерадости обозначим «grief»- горе.

С целью характеристики возможных причин и способов объективации эмоционального состояния радости и нерадости в сопоставляемых языках в качестве фактического материала были обозначены тексты классической русской и английской литературы, в которых ярко отражена национально-культурная специфика.

В большинстве случаев в качестве ведущих причин проявления изучаемых эмоций выступают какое-либо событие, либо соответствующие состояния, в которых пребывает одушевленный субъект.

Более детальная характеристика причин, обусловливающих рассматриваемые нами эмоциональные состояния, позволяет выделить следующие ситуации проявления эмоций радости: 1) приезд субъекта куда-либо, 2) получение положительно окрашенного известия, 3) окончание ожидания чего-либо, 4) неожиданная встреча или запланированный визит, 5) восхищение от увиденного.

В рамках проявления эмоций нерадости в качестве преобладающих выделены следующие ситуации: 1) неоправдавшиеся ожидания субъекта, 2) совершение субъектом каких-либо действий, не приносящих результата, 3) разочарование в объекте (человек, предмет).

Представленные ситуации объективируются в русском и английском языках различными языковыми средствами. В рамках статьи остановимся на группе аффективных средств, являющихся наиболее частотными.

В фактическом материале английского языка в данной группе представлены преимущественно прилагательные, указывающие непосредственно на определенную степень проявления радости / нерадости - восхищения, удивления / грусти, отвращения. Приведем примеры/

«It is wonderful, - replied Wickham», - в данном случае аффективное прилагательное «wonderful» указывает на восхищенное эмоциональное состояние субъекта;

«It is amazing to me!», - аффективное прилагательное amazing также подчеркивает восхищенное и удивленное эмоциональное состояние говорящего;

«That there is nothing so bad as parting with one's friends», - оценочное прилагательноеаффектив «bad» выражает проявление эмоционального состояния грусти;

«I declare I do not know a more awful object than Darcy», - оценочное прилагательноеаффектив «awful» указывает на переживаемую субъектом неприятную эмоцию отвращения.

В качестве аффективов могут выступать также существительные или глаголы, например: «She smiled at him», «He loved a crowd», «Julia spent a happy morning».

Обратимся к материалу русского языка, где также востребованной является группа аффективных средств. Приведем примеры:

«Прекрасно! В какие же места?», - в данном случае наречие «прекрасно» выражает аффект или эмоцию радости-восхищения;

«Ребята сделали отлично!», - аналогичный пример, где наречие «отлично» выражает эмоцию радости-удовлетворения; 
«Ужасное невежество!», - в данном случае эмоция грусти-разочарования выражена при помощи оценочно окрашенного прилагательного высокой интенсивности «ужасное», которое усиливает качество субъекта, номинированное существительным "невежество";

«Зачем же выставлять напоказ бедность нашей жизни и наше грустное несовершенство» - аналогичный пример, где оценочное прилагательное «грустное» усиливает отрицательно окрашенное абстрактное существительное.

В качестве аффективов в русском языке отмечены также прямые номинации собственно проявления эмоции радости и соответствующих эмоциональных действий существительное "радость" и соответствующие глагольные единицы: «Маргарита улыбнулась и сделала попытку отодвинуть от себя стакан»; «Радость загорелась в маленьких глазках Штурман Жоржа».

Фактический материал исследования показал, что в отличие от английского языка в русском языке для выражения эмоций радости / нерадости в качестве аффективов используются также однозначные междометия, которые даже вне контекста могут выступать как маркеры данных эмоций:

В этом-то вся драма, - думал он. - $\mathbf{A x}, \mathbf{a x}, \mathbf{a x ! » , ~ - ~ м е ж д о м е т и е ~ « а х » , ~ п у н к т у а ц и о н н о ~}$ усиленное восклицанием, выражает эмоцию грусти-разочарования;

«Батюшки! на что ты похож!», - эмоциональное междометие «батюшки», также усиленное восклицательной конструкцией, выражает неприятное удивление;

«За здоровье нашего бывшего товарища и храброго генерала князя Серпуховского. Ура! Ура!», - эмоциональное междометие «ура», также представленное в рамках восклицательной конструкции и усиленное номинативным повтором, выражает радость.

Таким образом, приведенные междометия могут самостоятельно эксплицировать эмоции радости / нерадости и являются в фактическом материале устойчивыми репрезентантами данных эмоций. Так, употребление междометия «ах» с целью объективации испытываемой грусти или разочарования достаточно распространено в русском языке.

В английском языке в качестве репрезентантов анализируемых эмоций отдельную группу составляют общепринятые и устоявшиеся фразы-клише. Например, устойчивые выражения:

«Mother, Mother, I am so happy!», - радость выражается устойчивой идиомой;

«Don't look so sad. I am as happy today as you were twenty years ago», - в данном случае мы видим указание сразу на две эмоции. Во-первых, грусти, актуализируемой при помощи устойчивого выражения «look so sad». Во-вторых, радости, выраженной посредством грамматической конструкции «as happy as», являющейся устойчивым выражением.

В обоих языках в качестве отдельного способа выражения эмоций радости / нерадости можно выделить синтаксические эмфатические конструкции, например:

«What a pity it is», - в данном случае с помощью эмфатической конструкции выражается эмоция грусти-сожаления;

«Как же, право, жаль», - аналогичный пример употребления эмфатической конструкции в русском языке для выражения эмоции грусти-сожаления.

Отдельно отметим, что радостные чувства, связанные с симпатией и эмоциональной привязанностью одного человека к другому, в обоих языках выражаются при помощи употребления соответствующих лексем-обращений. Так, для английского языка характерно использование следующих эмотивных слов-обращений, выражающих приятные эмоции: dear, honey, sweetheart и др. В русском языке более употребительными при выражении радости являются уменьшительно-ласкательные формы прилагательных: зайка, деточка, голубушка и др.

Таким образом, анализ фактического материала показал следующее. Эмоции радости / нерадости являются универсальными и "легкими" для понимания как в английской, так и в русской лингвокультурах. В целом, способы выражения данных эмоций в обоих языках обнаруживают достаточно много сходств как с точки зрения лексики, так и синтактики. 
Например, употребление аффективных лексических единиц, которыми являются эмоционально окрашенные прилагательные и наречия, позволяют выразить эмоциональное состояние субъекта в русском и английском языках. Однако в английском языке репрезентативна группа эмотивных обращений, в роли которых выступают прилагательные с окраской ласкательности, подчеркивающие эмоциональную привязанность субъекта, в русском языке - уменьшительно-ласкательные формы существительных. Помимо этого, в русском языке, в отличие от английского, в качестве ведущих средств выражения рассматриваемых эмоциональных проявлений радости и нерадости выступает группа междометий, среди которых частотными будут междометия «батюшки», «ура», «ах», причем междометие «ах» может выразить большой спектр эмоций от радости до разочарования.

На уровне синтаксиса в обоих языках отмечена такая общая тенденция, как использование интонационно-экспрессивных и эмфатических восклицательных конструкций.

Дальнейшая подробная характеристика способов выражения в сопоставляемых языках обозначенных ситуаций радости и нерадости на следующем этапе исследования позволит составить типологию языковых средств объективации рассматриваемых эмоциональных проявлений и выявить национально-культурную специфику сложившихся представлений об эмоциональной деятельности субъекта в неблизкородственных лингвокультурах.

1. Изард, Кэррол Э. Психология эмоций / Кэррол Э. Изард ; пер. с англ. В. Мисник, А. Татлыбаев. - Москва.: Питер, 2009. - 460 c.

2. Austen, J. Pride and prejudice / J Austen - Moscow : Eksmo, 2016. - 381 p.

3. Гоголь, Н. В. Мертвые души : поэма : том первый / Н. В. Гоголь. - Москва : Детская литература, 2020. - 445 c.

4. Шаховский, В.И. Лингвистическая теория эмоций : монография / В. И. Шаховский. - Москва : Гнозис, 2008. $-414 \mathrm{c}$.

5. Малов, А. А. Аффективные рейтинги номинаций базовых эмоций в русском и английском языках : диссертация ... кандидата филологических наук : 10.02.20 / Малов Алексей Александрович; [Место защиты: Ур. гос. пед. ун-т]. - Пермь, 2017. - 165 с.

6. Уайльд, O. The Picture of Dorian Gray / О. Уайльд ; адаптация текста, коммент., упражнения, слов. Е. Г. Вороновой. - Москва : Айрис-пресс, 2012. - 214 с.

7. Толстой, Л. Н. Анна Каренина / Л. Н. Толстой. Ч. 5-8. - М. : Радуга, - 583 с.

8. Булгаков, М. А. Мастер и Маргарита / М. Булгаков. - М. : Пан пресс, 2004. - 296 с.

9. Thackeray, W. Vanity Fair : Novel/ W. Thackeray. - M. : Exmo, 2002. - 734 c.

10. Maugham, W. S. The Moon and Sixpence // Liteka - URL: https://liteka.ru/english/library/568-the-moon-andsixpence (дата обращения: 03.12.2021).

\section{Пухаева А.А. \\ Языковые средства реализации гендерной асимметрии}

Северо-Осетинский государственный университет им. К.Л.Хетагурова (Россия, Владикавказ)

doi: 10.18411/trnio-01-2022-117

\section{Аннотация}

В статье гендерная асимметрия рассматривается как андроцентрическое явление, тесно связанное с идеологией феминизма и как непропорциональная представленность мужчин и женщин в различных сферах жизни. женщина.

Ключевые слова: гендерная асимметрия, андроцентризм, гендерология, мужчина,

\section{Abstract}

In the article gender asymmetry is considered as an androcentric phenomenon, closely related to the ideology of feminism and as a disproportionate representation of men and women in various spheres of life.

Keywords: gender asymmetry, androcentrism, genderology, man, woman. 